\title{
Fetal Bile Salt Metabolism
}

\section{THE METABOLISM OF SODIUM CHOLATE- ${ }^{14} \mathrm{C}$ IN THE FETAL DOG}

\author{
B. T. Jackson, R. A. Smallwood, G. J. Piasecki, A. S. Brown, \\ H. F. J. RAUSCHECKER, and R. LESTER \\ From the Departments of Medicine and Surgery, Boston University School of \\ Medicine, Boston, Massachusetts 02118
}

A B S T R A C T Cholate metabolism was studied in fetal dogs 1 wk before term and was compared with cholate metabolism in adult dogs. Tracer amounts of sodium cholate ${ }^{14} \mathrm{C}$ were administered to the fetus in utero by intravenous infusion over $6 \mathrm{hr}$. Fetal plasma disappearance, biliary excretion, tissue distribution, and placental transfer of cholate were measured over $10 \mathrm{hr}$.

Infused cholate $-{ }^{14} \mathrm{C}$ was cleared rapidly from fetal plasma principally by the fetal liver and to a minor extent by placental transfer to the mother. The taurine conjugate was formed in the fetal liver and was excreted into the proximal small intestine via the biliary tree. Indirect evidence for the functioning enterohepatic circulation of bile salt in the fetus was obtained.

Comparison with the results of similar experiments in adult dogs showed that the fetal liver was almost as efficient as the adult liver in the uptake, conjugation, and excretion of tracer amounts of cholate- ${ }^{14} \mathrm{C}$. The maximal rate of excretion of radiolabel attained by the fetus was somewhat slower than in the adult $(82.8$ $\pm 1.4 \%$ and $96.1 \pm 4.0 \%$ [mean $\pm \mathrm{sE}$ ] of the infusion rate, respectively), and the proportion of the total dose excreted by the fetal liver during $10 \mathrm{hr}$ was smaller $(81.4 \pm 1.3 \%$ vs. $96.6 \pm 4.4 \%)$. This difference could be only partly accounted for by placental transfer (2.8 $\pm 0.6 \%$ of the fetal dose).

Labeled cholate and taurocholate were excreted by the fetus at similar rates, which suggests that, under the conditions of study, conjugation had little influence on the rate of transfer of cholate across the liver cell.

It is concluded that the fetal dog, 1 wk before birth,

This work was partially completed during the tenure of an Established Investigatorship of the American Heart Association held by Dr. Jackson. Dr. Lester is the recipient of U. S. Public Health Service Career Development Award AM 12,127.

Received for publication 1 June 1970 and in revised form 17 February 1971. has a remarkably mature and efficient mechanism for the uptake and excretion of cholate.

\section{INTRODUCTION}

In the adult, bile salts play a central role both in the formation of bile and in the dispersion of the gut lumen contents (1-4). Despite recent interest in fetal hepatic and intestinal function, there has been no prior attempt to characterize fetal bile salt metabolism. Observations have been confined to identifying and quantitating bile salt in perinatal gall bladder bile and intestinal content (5-9).

Previously described intra-uterine surgical techniques (10) were, therefore, modified in order to implant biliary catheters in near-term fetal dogs and thus to permit detailed and prolonged studies of fetal bile salt metabolism. The specific methods employed avoided loss of amniotic fluid, permitted continuous monitoring of fetal cardiovascular status, and resulted in the maintenance of physiological fetal conditions during investigation.

Tracer doses of sodium cholate $-{ }^{14} \mathrm{C}$ were infused into fetuses and into nonpregnant adults. The results establish that the hepatic uptake, conjugation, and excretion of cholate are almost as efficient in the near-term fetus as in the adult.

\section{METHODS}

Surgical preparation. Experiments were carried out in pregnant pedigreed beagles from 1 to $3 \mathrm{yr}$ old between the 56 th and 58th day of pregnancy (total gestation period, 63 days). Animals were worm-free and vaccinated against canine distemper and hepatitis.

In one group of experiments $\left(F D_{1-3}\right)$, the carotid artery and jugular vein of a fetus in utero were cannulated, and a bile fistula was placed in the mother. Five further experiments $\left(\mathrm{FD}_{4-9}\right)$ were handled as above, but, in addition, a catheter was implanted in the fetal common bile duct. Five nonpregnant adult dogs $\left(\mathrm{AD}_{1-5}\right)$ were studied with bile fistulas and femoral arterial and venous cannulas. The tech- 


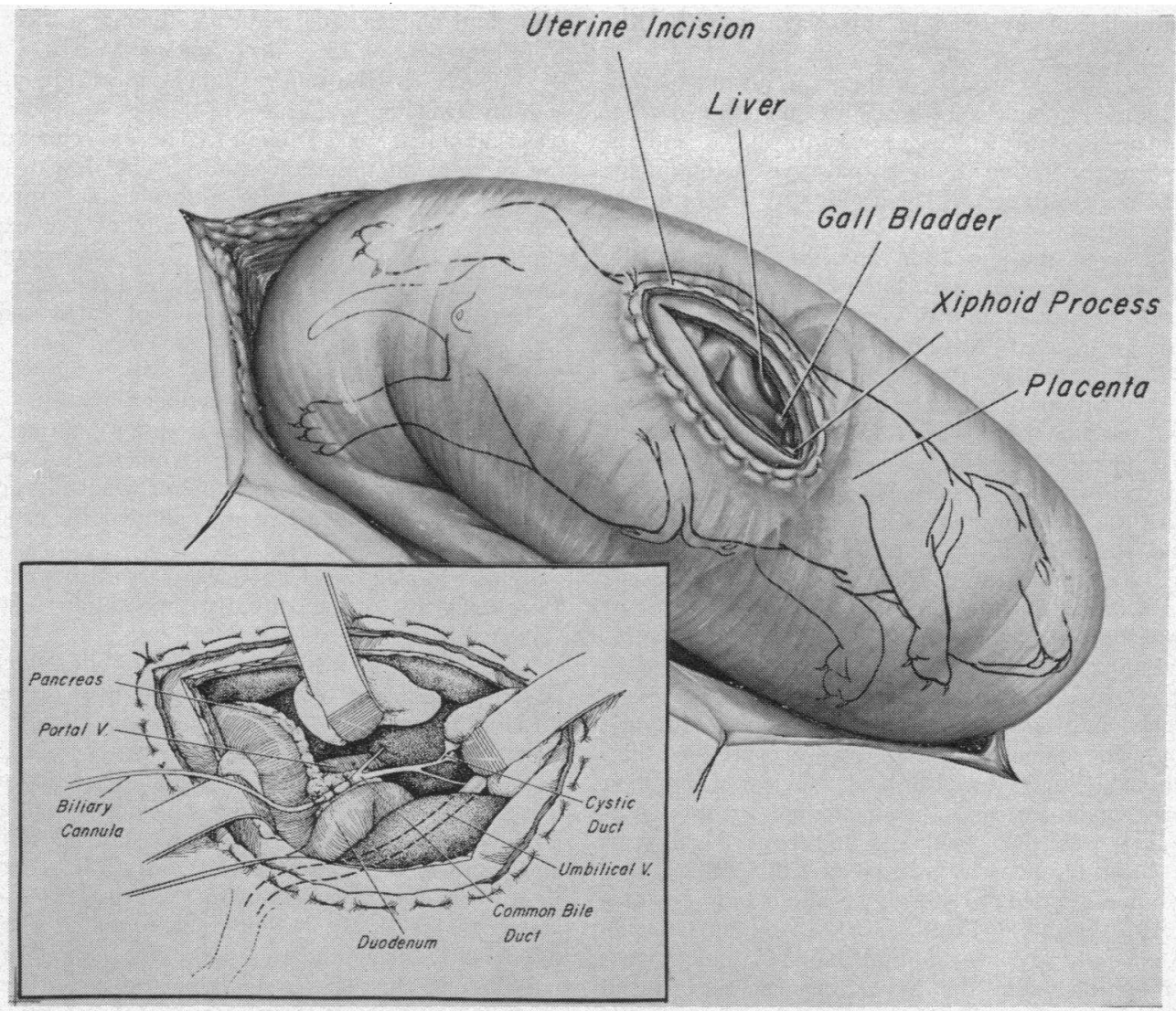

Figure 1 Fetal bile duct cannulation. The broad view shows the general approach for cannulation of the common bile duct in the dog fetus in utero. The stitch surrounding the uterine and fetal incisions binds the uterus and fetus together and prevents loss of amniotic fluid. Inset reveals the details of the biliary cannulation. Note the proximity of the umbilical vein to the operative field.

nical details of all major operative procedures are included in the description below of the more complex of the fetal preparations.

Anesthesia was induced with $7-15 \mathrm{ml}$ of sodium thiamylal (surital sodium) intravenously and maintained with a halothane-oxygen mixture in a nonrebreathing system, using an intermittent positive pressure respirator. A midline laparotomy was performed, and a portion of the uterus containing a suitably positioned fetus was exposed.

Fetal bile duct cannulation was carried out by utilizing a "marsupializing" incision in the right subcostal region of the fetus as shown in detail in Fig. 1. This approach comprised the placement of a circular stitch attaching the fetal skin to the uterine wall so that an incision within the encircled area could be made in the fetus without removing it from the uterus and without losing amniotic fluid (10). The subcostal incision was carried into the abdomen, the fetal gall bladder was aspirated, and the cystic duct was ligated. The portal area was exposed, and either a polyvinyl or polyethylene catheter (I.D. 0.011 in., 0.D. 0.023 in.) was inserted into the common bile duct and tied in place. Avoidance of medial retraction against the umbilical vein during this step was necessary to insure the survival of the fetus. Fetal and uterine incisions were closed, and the fetus was released from its attachment to the uterus.
A second "marsupializing" incision was performed in the cervical region of the fetus to allow cannulation of the jugular vein (silicone rubber tubing, I.D. 0.025 in., 0.D. 0.047 in.) and carotid artery (polyvinyl tubing, I.D. 0.023 in., o.D. 0.038 in.). Incisions were closed, and the fetus was again released from the uterus and left floating free within the amniotic space. Finally, ECG electrodes were implanted directly through the uterine wall into the two forelegs and one hindleg of the fetus (11).

The maternal cystic duct and cystic vessels were ligated, and the common bile duct was cannulated with a polyvinyl catheter (I.D. 0.053 in., 0.D. 0.085 in.). All cannulas and the ECG leads were exteriorized through the maternal incision, which was then closed.

Preparation of taurocholate $-{ }^{14} \mathrm{C}$. Taurocholate $-{ }^{14} \mathrm{C}$ was prepared biosynthetically from chromatographically pure cholate $-{ }^{14} \mathrm{C}$ (New England Nuclear Corp., Boston, Mass.). Wistar rats $(200-300 \mathrm{~g})$ were prepared with bile fistulas, and $15-20 \mathrm{hr}$ later $4-5 \mu \mathrm{g}$ of cholate- ${ }^{14} \mathrm{C}$ (SA $3.04 \times 10^{5}$ $\mathrm{dpm} / \mu \mathrm{g}$ ) was injected intravenously. Bile was collected over the following hour, and taurocholate $-{ }^{14} \mathrm{C}$ was purified by preparative thin-layerchromatography (TLC) of the rat bile on Silica Gel $\mathrm{H}$ in two systems: system I, butanolwater-acetic acid $(85: 10: 5)$; and system II, chloroformmethanol-water-acetic acid $(65: 20: 10: 5)$ (12). Specific 
activity of tauracholate prepared in this way was $2.50-3.12$ $\times 10^{4} \mathrm{dpm} / \mu \mathrm{g}$.

Experimental design. Throughout the experimental period in all studies light halothane anesthesia was maintained. The mother was infused with $5.0 \%$ dextrose in $0.9 \%$ sodium chloride at $50 \mathrm{ml} / \mathrm{hr}$. Nine fetuses and five nonpregnant adult animals were studied (Table I). In experiments $\mathrm{FD}_{1-8}$ (no fetal biliary cannula), a $24 \mathrm{hr}$ recovery interval was allowed between the operation and the study: in the intervening period, the maternal biliary cannula was attached to a collecting tube, and all cannulas and wires were covered by a protective dressing. In experiments $F D_{4-9}$ (with fetal biliary cannula), the study was initiated immediately after completion of surgery. During each fetal experiment, fetal and maternal ECG's and fetal arterial blood pressure were monitored utilizing a Sanborn 350 series recorder and calibrated physiologic pressure transducer. In these studies the fetal heart rate ranged from 125 to 160 beats $/ \mathrm{min}$, and the arterial pressure from $35 / 25$ to $45 / 35$ $\mathrm{mm} \mathrm{Hg}$. The nonpregnant adult dog studies $\left(\mathrm{AD}_{1-5}\right)$ were completed on the day of operation.

In fetal experiments, tracer amounts of chromatographically pure sodium cholate- ${ }^{14} \mathrm{C}\left(\mathrm{FD}_{1-7}\right)$ or sodium taurocholate ${ }^{14} \mathrm{C}\left(\mathrm{FD}_{8,8}\right)$ were administered to the fetus via the indwelling jugular vein catheter, using a calibrated Harvard infusion pump. The cholate $-{ }^{14} \mathrm{C}$ dose was prepared by dissolving cholic acid- $-{ }^{14} \mathrm{C}$ (New England Nuclear Corp.) in $1 \%$ sodium carbonate. An appropriate aliquot of this solution $(50-150 \mu \mathrm{l})$ was then made up to about $3 \mathrm{ml}$ with $0.9 \%$ sodium chloride and was infused at $0.408 \mathrm{ml} / \mathrm{hr}$ over $6 \mathrm{hr}$ (total volume infused $=2.45 \mathrm{ml}$ ). Sodium taurocholate${ }^{14} \mathrm{C}$ was made up directly in $3 \mathrm{ml}$ of $0.9 \%$ sodium chloride and infused in the same way. Fetal blood samples were obtained at intervals from the indwelling carotid arterial catheter, and half-hourly collections of fetal and maternal bile were made. Maternal blood was taken by multiple venepunctures from the external jugular vein. At the end of each experiment fetus and mother were autopsied. Fetal tissues including all major organs were kept for analysis, together with samples of amniotic fluid, placenta, maternal urine and plasma, and maternal liver and kidney. Specimens were stored at $-15^{\circ} \mathrm{C}$ until analyzed.

Similarly, in the adult studies tracer amounts of labeled sodium chloate $\left(\mathrm{AD}_{1-3}\right)$ or sodium taurocholate $\left(\mathrm{AD}_{4,5}\right)$ were administered (Table I). The experimental design was the same as in the fetal studies. The dose was made up to $10 \mathrm{ml}$ with $0.9 \%$ sodium chloride and infused into the femoral vein over $6 \mathrm{hr}$ at $1.4 \mathrm{ml} / \mathrm{hr}$; the experiment was continued for a further $4 \mathrm{hr}$. Blood was sampled from the indwelling femoral arterial catheter, and bile samples were collected half-hourly. At the end of each study an autopsy was performed, and samples of liver, kidney, plasma, and urine were kept.

Analytical procedures. Radioactivity in bile, plasma, urine, and amniotic fluid was assayed in a Packard TriCarb liquid scintillation spectrometer as previously described (13). Solid tissues were weighed, and a weighed sample was homogenized and counted by established methods (14).

Fetal arterial blood samples were also analyzed for $\mathrm{pH}$, $\mathrm{P}_{\mathrm{CO}_{2}}$, and $\mathrm{P}_{\mathrm{O}_{2}}$ using an Instrumentation Laboratory $\mathrm{pH} /$ Gas analyzer, model 113.

To characterize the components of bile which were radiolabeled, fetal and maternal bile samples were subjected to TLC (15) on Silica Gel G in system II and in an isoamyl acetate-propionic acid- $n$-propanol-water $(4: 3: 2: 1)$ system (system III), along with taurocholate, taurochenodeoxycholate, glycocholate, and glycochenodeoxycholate standards. The plates were then developed, scraped into count vials, and counted as previously described (13). Bile was also run in a second system (system IV), isooctane-ethyl acetateacetic acid $(10: 10: 2)$ with unconjugated cholate, chenodeoxycholate, deoxycholate, and lithocholate standards. Bile was run in this system both before and after alkaline hydrolysis in five volumes of $1 \mathrm{~N} \mathrm{NaOH}$ at three atmospheres and $250^{\circ} \mathrm{C}$ over $3 \mathrm{hr}$.

Bile salt concentrations in fetal hepatic and gall bladder bile were measured enzymatically using $\beta$-hydroxy steroid dehydrogenase (Worthington Biochemical Corp., Freehold, N. J.) (16).

TABLE I

Administration of Radiolabeled Sodium Cholate and Sodium Taurocholate to Fetal and Adult Dogs

\begin{tabular}{|c|c|c|c|c|c|c|c|c|}
\hline \multirow[b]{2}{*}{ Exp. } & \multirow[b]{2}{*}{ Animal } & \multirow[b]{2}{*}{ Weight } & \multicolumn{2}{|c|}{ Cholate-14C dose } & \multicolumn{2}{|c|}{ Taurocholate-14 C dose } & \multirow{2}{*}{$\begin{array}{l}\text { Duration } \\
\text { of infu- } \\
\text { sion }\end{array}$} & \multirow{2}{*}{$\begin{array}{l}\text { Duration } \\
\text { of study }\end{array}$} \\
\hline & & & Amount & Specific activity & Amount & Specific activity & & \\
\hline & & $g$ & $\mu g$ & $d p m / \mu g$ & $\mu g$ & $d p m / \mu g$ & $h r$ & $h r$ \\
\hline $\mathrm{FD}_{1}$ & Fetal dog & 228 & 8.0 & $3.40 \times 10^{5}$ & - & - & 6 & 10 \\
\hline $\mathrm{FD}_{2}$ & Fetal dog & 220 & 26.0 & $3.40 \times 10^{5}$ & - & 一 & 6 & 10 \\
\hline $\mathrm{FD}_{3}$ & Fetal dog & 230 & 25.1 & $3.40 \times 10^{5}$ & - & - & 6 & 10 \\
\hline $\mathrm{FD}_{4}$ & Fetal dog & 225 & 14.1 & $3.04 \times 10^{5}$ & - & - & 6 & 6 \\
\hline $\mathrm{FD}_{5}$ & Fetal dog & 333 & 13.3 & $3.04 \times 10^{5}$ & - & - & 6 & 10 \\
\hline $\mathrm{FD}_{6}$ & Fetal dog & 312 & 15.0 & $3.04 \times 10^{5}$ & - & - & 6 & 10 \\
\hline $\mathrm{FD}_{7}$ & Fetal dog & 300 & 15.4 & $3.04 \times 10^{5}$ & - & - & 6 & 10 \\
\hline $\mathrm{FD}_{8}$ & Fetal dog & 267 & - & - & 45 & $2.50 \times 10^{4}$ & 6 & 10 \\
\hline $\mathrm{FD}_{9}$ & Fetal dog & 244 & - & - & 52 & $2.50 \times 10^{4}$ & 6 & 10 \\
\hline $\mathrm{AD}_{1}$ & Adult dog & 9500 & 27.7 & $3.40 \times 10^{5}$ & - & - & 6 & 10 \\
\hline $\mathrm{AD}_{2}$ & Adult dog & 6000 & 13.8 & $3.04 \times 10^{5}$ & - & - & 6 & 10 \\
\hline $\mathrm{AD}_{3}$ & Adult dog & 9400 & 16.6 & $3.04 \times 10^{5}$ & - & - & 6 & 10 \\
\hline $\mathrm{AD}_{4}$ & Adult dog & 7100 & - & - & 103 & $3.12 \times 10^{4}$ & 6 & 10 \\
\hline $\mathrm{AD}_{5}$ & Adult dog & 7900 & - & - & 123 & $3.12 \times 10^{4}$ & 6 & 10 \\
\hline
\end{tabular}


A

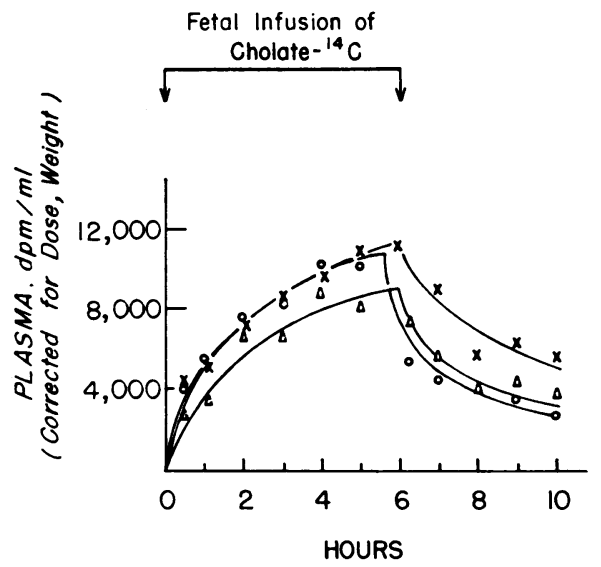

B
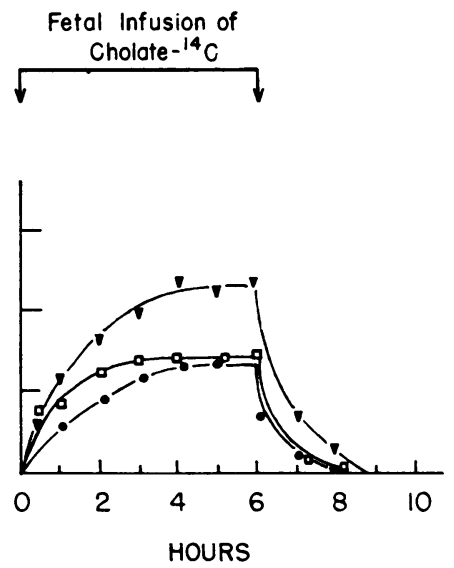

FIGURE 2 Changes in fetal plasma radioactivity during and after $6 \mathrm{hr}$ i.v. infusion of tracer amounts of cholate- ${ }^{14} \mathrm{C}$. (A) $\mathrm{FD}_{1-3}$, without bile fistulas. (B) $\mathrm{FD}_{5-7}$, with bile fistulas (data on plasma radiolabel not available for $\mathrm{FD}_{4}$ ). Values have been corrected for dose administered and fetal weight to allow direct comparison of the curves.

\section{RESULTS}

Effects of experimental manipulation on the fetus. The fetuses remained in excellent condition throughout the experiment, whether or not a $24 \mathrm{hr}$ recovery period between the time of surgery and the study were allowed. Heart rates and blood pressure levels showed little tendency to decrease, and the ECG tracings remained virtually unaltered. The only exception was FD4, which appeared to be in good condition until a rapid deterioration in the ECG tracing caused us to terminate the study prematurely. Fetal arterial blood $\mathrm{pH}, \mathrm{P}_{\mathrm{co}_{2}}$, and $\mathrm{P}_{\mathrm{O}_{2}}$ were determined in three fetuses and were found to correspond to those obtained in previous studies of fetal hepatic function (17).

Bile salt metabolism in fetuses without external biliary fistulas $\left(F D_{1-s}\right)$. The changes in ${ }^{14} \mathrm{C}$ activity in fetal plasma are shown in Fig. 2A. These changes were very similar in the three fetuses with the curves rising asymptotically to a maximum by the end of the infusion, however, without attaining a plateau. When the infusion ceased at $6 \mathrm{hr}$, the radioactivity levels dropped abruptly. However, there was still detectable radioactivity in plasma at the termination of study. Assuming a plasma volume of $9 \%$ of the fetal weight, ${ }^{1}$ it could be calculated that at the end of the infusion less than $5 \%$ of the total dose infused remained in the plasma. By the end of the study, these levels had fallen to $1-2 \%$.

The distribution of radioactivity at the end of $10 \mathrm{hr}$ is shown in Table II and Fig. 3. By far the largest

${ }^{1}$ Novy, M. J., G. J. Piasecki, and B. T. Jackson. Unpublished data. proportion of the ${ }^{14} \mathrm{C}$ label was recovered from the fetal gall bladder bile and intestinal contents (62.9 $\pm 3.7 \%$, mean $\pm \mathrm{SE})$. Most of this total was found in fetal gall bladder bile, but up to one-sixth (i.e. $10 \%$ of the dose) was found in the proximal small intestine. The fetal liver contained $5.1 \pm 1.7 \%$ of the dose. The total liver uptake of labeled cholate, i.e. the sum of the radioactivity excreted into the gall bladder and proximal intestine plus that remaining in the liver, was 68.0 $\pm 2.1 \%$. Small amounts of radioactivity were found in fetal urine, fetal kidneys, amniotic fluid, and placenta, in addition to that remaining in fetal plasma.

Some of the cholate ${ }^{-14} \mathrm{C}$ was transferred across the placenta where it appeared in the mother's bile and urine. At no point during the study was any radio-
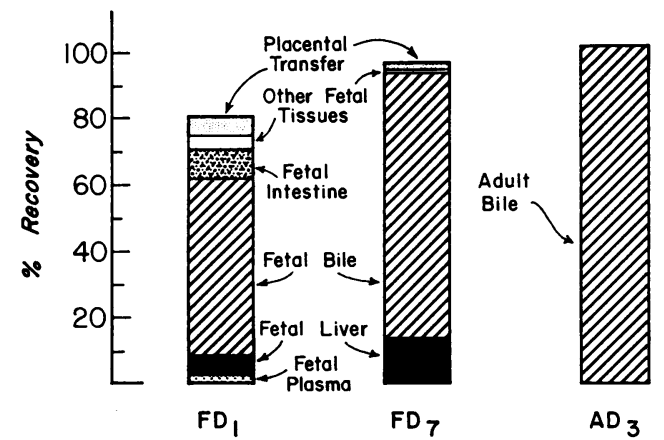

FIgURE 3 Final distribution of radioactivity after $10 \mathrm{hr}$ in three representative experiments. $\mathrm{FD}_{1}$, fetal dog without a bile fistula; $\mathrm{FD}_{7}$, fetal dog with a bile fistula; $\mathrm{AD}_{\mathbf{3}}$, adult dog with a bile fistula. 
TABLE II

Recovery of Radiolabel at Termination of Studies in Fetal Dogs

\begin{tabular}{|c|c|c|c|c|c|c|c|c|c|}
\hline Exp. & $\begin{array}{c}\text { Fetal } \\
\text { plasma }\end{array}$ & $\begin{array}{l}\text { Fetal } \\
\text { liver }\end{array}$ & $\begin{array}{c}\text { Fetal } \\
\text { bile }\end{array}$ & $\begin{array}{c}\text { Fetal } \\
\text { intestine }\end{array}$ & $\begin{array}{l}\text { Other } \\
\text { fetal } \\
\text { tissues }\end{array}$ & $\begin{array}{c}\text { Maternal } \\
\text { plasma }\end{array}$ & $\begin{array}{c}\text { Maternal } \\
\text { bile }\end{array}$ & $\begin{array}{l}\text { Maternal } \\
\text { urine }\end{array}$ & Total \\
\hline & $\%$ dose & $\%$ dose & $\%$ dose & $\%$ dose & $\%$ dose & $\%$ dose & $\%$ dose & $\%$ dose & $\%$ dose \\
\hline$F D_{1}$ & 2.0 & 5.8 & 53.6 & 9.6 & 3.5 & 0.0 & 2.2 & 3.3 & 80.0 \\
\hline $\mathrm{FD}_{2}$ & 1.3 & 7.2 & 57.0 & 0.2 & 2.2 & 0.0 & 1.1 & 2.6 & 71.6 \\
\hline $\mathrm{FD}_{3}$ & 1.4 & 2.3 & 58.8 & 9.5 & 1.8 & 0.0 & 1.0 & 0.6 & 75.4 \\
\hline $\mathrm{FD}_{4}$ & 2.0 & 7.5 & 62.8 & 0.0 & 0.7 & 0.0 & —* & 0.0 & 73.0 \\
\hline $\mathrm{FD}_{5}$ & 0.0 & 1.4 & 83.7 & 0.0 & 0.1 & 0.0 & 2.3 & 0.0 & 87.5 \\
\hline $\mathrm{FD}_{6}$ & 0.0 & 4.1 & 80.6 & 0.0 & 0.2 & 0.0 & 1.9 & 0.0 & 86.8 \\
\hline $\mathrm{FD}_{7}$ & 0.0 & 13.8 & 80.0 & 0.0 & 0.1 & 0.0 & 1.9 & 0.0 & 95.8 \\
\hline $\mathrm{FD}_{8}$ & 0.0 & 4.0 & 82.4 & 0.0 & 2.9 & 0.0 & 0.7 & 0.0 & 90.0 \\
\hline $\mathrm{FD}_{9}$ & 0.0 & 9.6 & 82.0 & 0.0 & 2.6 & 0.0 & 1.7 & 0.9 & 96.8 \\
\hline
\end{tabular}

* Maternal bile duct not catheterized.

activity detected in maternal plasma nor was any found in the liver or kidneys. The ${ }^{14} \mathrm{C}$ label appearing in the mother's bile and urine was therefore taken as a measure of placental transfer. Maternal biliary excretion of radioactivity is shown in Fig. 4A. The ${ }^{14} \mathrm{C}$ label was detected initially in maternal bile at $1-1 \frac{1}{2} \mathrm{hr}$ after the start of the infusion, and thereafter it continued to accumulate slowly until the end of the study. The maximum rate of accumulation in two of the three experiments occurred well after the end of the infusion. The eventual total accumulation was only $1.4 \pm 0.4 \%$ of the dose infused into the fetus. The appearance of some ${ }^{14} \mathrm{C}$ label in maternal urine and its delayed excretion in maternal bile were probably due to the sluggish initial maternal bile flow which followed the $24 \mathrm{hr}$ period between operation and experiment, and which may have been the result of operative trauma. In subsequent studies without the recovery period, initial maternal bile flow was 3-4 times faster, and there was an earlier peak of excretion of radioactivity (Fig. 4B). Moreover, no radioactivity appeared in maternal urine (Table II).

All fetal and maternal bile samples were chromatographed directly on Silica Gel G in systems II and III and both before and after alkaline hydrolysis in system IV. $94.5 \pm 3.3 \%$ of the radiolabel was present as taurocholate $-{ }^{14} \mathrm{C}$. No other peaks of radioactivity could be detected.

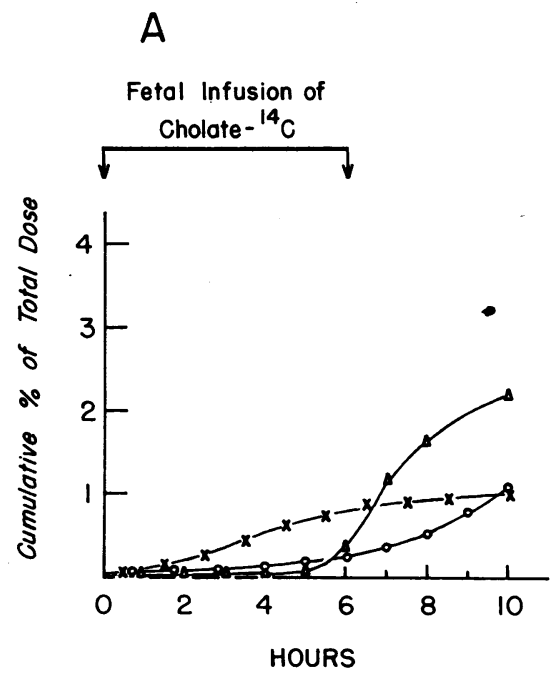

B

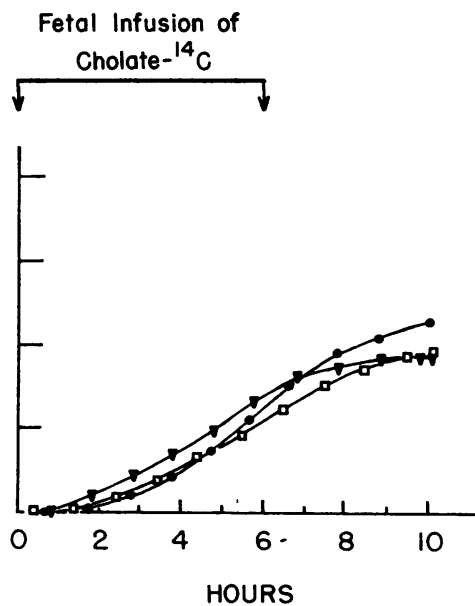

FIGURE 4 Maternal biliary excretion of radiolabel after the infusion of cholate $-{ }^{14} \mathrm{C}$ to the fetus. (A) $\mathrm{FD}_{1-8}$, in these experiments radiolabel was found in maternal urine (see text). (B) $\mathrm{FD}_{5-7}$, in which no radiolabel was recovered from maternal urine. Maternal bile duct not catheterized in FD. 
A

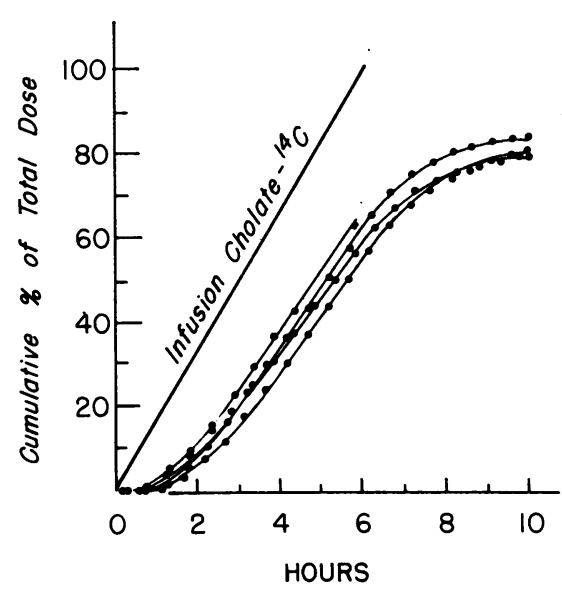

B ADULT

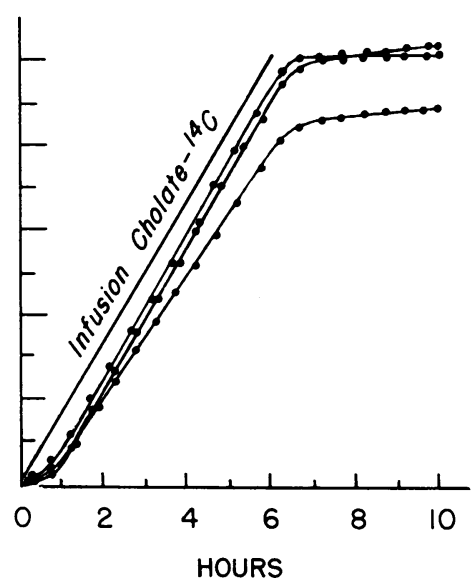

FIGURE 5 Excretion of radiolabel in bile after the infusion of labeled sodium cholate in (A) fetuses with external biliary fistulas ( $F D_{4-7}$ ), and (B) nonpregnant adult dogs $\left(A D_{1-3}\right)$. Both infusion and excretion of label are depicted as a cumulative per cent of the total dose. Comparison of the slope of the infusion line with that of the linear portion of the excretion curves gives a maximal excretion rate in the adult of $96.1 \pm 4.0 \%$ of the infusion rate and in the fetus of $82.8 \pm 1.4 \%$.

Bile salt metabolism in fetuses with external biliary fistulas $\left(F D_{4-9}\right)$. Fetuses with bile fistulas infused with sodium cholate- ${ }^{14} \mathrm{C}$ (Fig. 2B) showed changes in plasma radioactivity roughly similar to those without bile fistulas (Fig. 2A). There were, however, several clear differences. The mean peak level of radioactivity was lower in the group with fistulas $(P<0.05)$, and a plateau was reached before the end of the infusion. Moreover, after $6 \mathrm{hr}$ (termination of infusion), the fall in plasma radioactivity was more striking in this group so that by $8-9 \mathrm{hr}$ they had no detectable radioactivity in their plasma.

Maternal biliary excretion of ${ }^{14} \mathrm{C}$ label (Fig. 4B) was somewhat greater in preparations $\mathrm{FD}_{4-0}$ than in $\mathrm{FD}_{1-3}$ $(2.0 \pm 0.1 \%$ of the dose vs. $1.4 \pm 0.4 \%)$ and less delayed. However, no radioactivity was recovered in maternal urine so that the over-all transfer of radiolabel across the placenta was in fact somewhat less than in $\mathrm{FD}_{1-3}(2.0 \pm 0.1 \%$ vs. $3.6 \pm 1.3 \%)$.

By far the largest proportion of the cholate- ${ }^{14} \mathrm{C}$ infused into the fetus appeared in fetal hepatic bile (Table II, Fig. 3). Fig. 5A shows the rate of accumulation of ${ }^{14} \mathrm{C}$ label in fetal bile in $\mathrm{FD}_{4-7}{ }^{14} \mathrm{C}$ label excretion followed a very similar pattern in all four fetuses. After an initial period of 3-4 hr, the radiolabel began to accumulate in bile in a linear fashion, and this maximal excretion rate was maintained until $\frac{1}{2}-\frac{3}{4} \mathrm{hr}$ after the end of the infusion. The maximum rate of accumulation of radiolabel in fetal bile could be directly compared with the infusion rate by comparing the slope of the linear portion of the excretion curve with that of the infusion line (Fig. 5A). This gave a maximal ${ }^{14} \mathrm{C}$ label excretion rate into fetal bile of 82.8 $\pm 1.4 \%$ of the infusion rate. The total amount of radioactivity appearing in fetal hepatic bile over $10 \mathrm{hr}$ was $81.4 \pm 1.3 \%$ of the dose. Again, essentially all (93.8 $\pm 3.1 \%$ ) of the ${ }^{14} \mathrm{C}$ label in fetal and maternal bile was identified by TLC as being in taurocholate. No radioactivity was found in the fetal kidneys and urine. In no experiment was radioactivity detected in maternal plasma at any point during the $10 \mathrm{hr}$.

The pattern of excretion of taurocholate- ${ }^{14} \mathrm{C}\left(\mathrm{FD}_{8,0}\right)$ was very similar to that of cholate $-{ }^{14} \mathrm{C}$ (Table II). Maximal rates of excretion of radiolabel were 82.4 and $83.0 \%$ of the infusion rate and were attained within 3-4 $\mathrm{hr}$. The total radioactivity appearing in fetal bile after $10 \mathrm{hr}$ was virtually the same as with cholate $-{ }^{14} \mathrm{C}$ infusions ( 82.4 and $82.0 \%$ vs. $81.4 \pm 1.3 \%$ of the dose).

Endogenous bile salt excretion in the fetus. The concentration of bile salt in initial fetal hepatic bile samples was $13.8-28.0 \mu \mathrm{moles} / \mathrm{ml}$, and initial bile salt excretion rates varied from 1.4 to $4.3 \mu$ moles $/ \mathrm{hr}$. Fetal gall bladder bile contained $40-170 \mu$ moles $/ \mathrm{ml}$ of bile salt, which indicates that the fetal gall bladder has a considerable capacity to concentrate bile.

Bile salt metabolism in the adult dog. Fig. 5B shows the biliary excretion of radiolabel in the three adult dogs $\left(A D_{1-3}\right)$ which had been infused over $6 \mathrm{hr}$ with tracer amounts of radioactive cholate. The pattern of excretion was similar to that seen in the fetus. After 
TABLE III

Recovery of Radiolabel at Termination of Studies in Adult Dogs

\begin{tabular}{ccrccc}
\hline Exp. & Plasma & \multicolumn{1}{c}{ Bile } & Urine & Liver & Total \\
\hline & $\%$ dose & $\%$ dose & $\%$ dose & $\%$ dose & $\%$ dose \\
$\mathrm{AD}_{1}$ & 0.0 & 88.3 & 0.8 & 0.0 & 89.1 \\
$\mathrm{AD}_{2}$ & 0.0 & 100.4 & 0.0 & 0.0 & 100.4 \\
$\mathrm{AD}_{3}$ & 0.0 & 101.1 & 0.0 & 0.0 & 101.1 \\
$\mathrm{AD}_{4}$ & 0.0 & 101.0 & 0.0 & 0.0 & 101.0 \\
$\mathrm{AD}_{5}$ & 0.0 & 101.7 & 0.0 & 0.0 & 101.7 \\
\hline
\end{tabular}

a short initial period, there followed a rapid linear accumulation of radiolabel in bile which persisted throughout the rest of the infusion and for a short time thereafter. There were, however, differences between adult and fetal curves. A constant, maximal excretion rate was attained within $1-1 \frac{1}{2} \mathrm{hr}$ (vs. $3-4 \mathrm{hr}$ in the fetus) and was maintained for a brief $10-15 \mathrm{~min}$ after the end of the infusion. This rate was higher in the adult ( $96.1 \pm 4.0 \%$ of the infusion rate) so that by the end of the infusion at $6 \mathrm{hr}, 85.5 \pm 4.4 \%$ of the dose had appeared in bile in the adult experiments compared with $59.8 \pm 1.9 \%$ in the fetus. The total amount of radioactivity appearing in bile over $10 \mathrm{hr}$ was $96.6 \pm 4.4 \%$ of the dose compared with $81.4 \pm 1.3 \%$ in fetal experiments. The radioactivity in adult bile was virtually all $(91.7 \pm 2.9 \%)$ in the form of taurocholate $-{ }^{14} \mathrm{C}$. The greater proficiency of the adult liver was also reflected by the fact that, in the adult, excretion of radiolabel was virtually complete within 1-2 hr of the end of the infusion, whereas the fetus continued to excrete appreciable amounts of ${ }^{14} \mathrm{C}$ label $4 \mathrm{hr}$ later. Thus the adult's excretion of cholate- ${ }^{14} \mathrm{C}$ occurred more rapidly and was more nearly complete.

There was no radioactivity found in the liver, kidney, or other tissues in the adult dog (Table III, Fig. 3), but small amounts were found in the urine in $\mathrm{AD}_{1}$. No radioactivity could be detected in multiple plasma samples during and after the infusion. As in the fetal studies, infusion of taurocholate $-{ }^{14} \mathrm{C}\left(\mathrm{AD}_{4, \mathrm{~s}}\right)$ produced a pattern of biliary excretion of radiolabel that was very similar to that following cholate $-{ }^{14} \mathrm{C}$ infusion. After an hour, radiolabel was excreted at a rate equal to the infusion rate, and essentially all the administered radioactivity was excreted by $6 \frac{1}{2}-7 \frac{1}{2} \mathrm{hr}$. No ${ }^{14} \mathrm{C}$ label was detected in plasma, liver, urine, or other tissues (Table III).

\section{DISCUSSION}

The present study examined in the near-term dog fetus one aspect of the coordinated functioning of liver and intestine, the transport of bile salt. It established that the fetal dog, 1 wk before term, possesses an efficient mechanism for the uptake and excretion of sodium cholate, a mechanism which closely resembles that of the adult.

Specifically, fetal plasma was rapidly cleared of tracer amounts of infused cholate $-{ }^{14} \mathrm{C}$. At the end of a $6 \mathrm{hr}$ infusion, the plasma level of ${ }^{14} \mathrm{C}$ label represented less than $5 \%$ of the total dose infused, i.e., over $95 \%$ had left the plasma. In the initial studies $\left(F D_{1-3}\right)$, the fact that ${ }^{14} \mathrm{C}$ label was ultimately recovered primarily from fetal liver and gall bladder bile (Table II) suggested that the rapid plasma clearance was largely due to uptake and excretion by the fetal liver. This was confirmed by subsequent studies ( $F D_{4-7}$, Fig. $5 \mathrm{~A}$ ) in which excretion of the ${ }^{14} \mathrm{C}$ label by the fetal liver was measured directly.

The over-all patterns of fetal and adult bile salt excretion were similar (Fig. 5). Both adult and fetus displayed an initial lag phase between the start of infusion of cholate- ${ }^{14} \mathrm{C}$ and the onset of excretion of radiolabel. Both reached maximal rates of excretion of ${ }^{14} \mathrm{C}$ label that approached the rate of infusion, and both excreted the major portion of the infused dose during the $10 \mathrm{hr}$ period of study. Moreover, virtually all of the administered cholate- ${ }^{14} \mathrm{C}$, as well as endogenous bile salt, was conjugated with taurine in adult and fetus.

Differences between the fetus and adult become apparent, however, upon closer examination of the data. The period between the start of infusion and attainment of maximal excretory rate averaged $2-3 \mathrm{hr}$ longer in the fetus than in the adult. In addition, the maximal rate of excretion in the adult equaled $96.1 \pm 4.0 \%$ of the infusion rate, whereas that in the fetus equaled 82.9 $\pm 1.4 \%$. At any point during the $6 \mathrm{hr}$ infusion and the $4 \mathrm{hr}$ postinfusion period, adult excretion exceeded that in the fetus. This difference was greatest at the end of the infusion when adult animals had excreted $85.5 \pm 4.4 \%$ of the dose compared with $59.8 \pm 1.9 \%$ by the fetus. At $10 \mathrm{hr}$ the percentages excreted by the adult and fetus were $96.6 \pm 4.4$ and $81.4 \pm 1.3$, respectively.

Fetal and adult dissimilarities in the excretion of bile salt can be fully assessed only when detailed data on endogenous plasma bile salt concentration, pool size, and maximal excretory rate become available. Examination of the isotopic data presented, however, does yield at least a partial clarification of this question and suggests that some step (or steps) in the over-all process of transport of bile salt to the liver, hepatic uptake, transport within the hepatocyte, cannalicular secretion, or biliary reabsorption is less effiecient in the fetus than in the adult.

The experimental results are not explained by differences in dose; tracer amounts of labeled bile salt were injected in all studies, with the amounts of exogenous bile salt excreted by the fetus being less than $1 \%$ of endogenous excertion. Similarly, the findings cannot be 
accounted for by the presence of a competing placental excretory mechanism as the total placental transfer averaged only $2.8 \pm 0.6 \%$ of the dose infused, not enough to account for the observed differences between fetus and adult. Moreover, inadequate fetal hepatic conjugation probably does not limit the fetus's ability to excrete tracer amounts of cholate since essentially all of the ${ }^{14} \mathrm{C}$ label appeared in bile in the form of the taurine conjugate, and since virtually identical results were obtained when taurocholate $-{ }^{14} \mathrm{C}$ was administered.

The observed differences between the adult and fetus may relate to the postexcretory phase of bile salt metabolism. Although the fate of bile salt after reaching the intestine was not studied directly in the present investigation, some evidence was obtained which suggested recycling of ${ }^{14} \mathrm{C}$ label from the gut to systemic plasma in animals with the biliary tree intact $\left(F D_{1-s}\right)$. Plasma concentrations of radiolabel in these animals continued to rise during infusion, showed a relatively slow initial disappearance after the infusion was stopped, and were still detectable at $10 \mathrm{hr}$ (Fig. 2A). These findings contrast with those in fetuses with biliary diversion in which the mean maximal plasma concentration of radiolabel was lower $(P<0.05)$ and values reached a plateau during infusion (Fig. 2B). In addition, in all fetuses with biliary diversion, the initial rates of disappearance after cessation of infusion were more rapid, and at $10 \mathrm{hr}$ no detectable radiolabel remained. Reabsorption of cholate from the intestine and its escape into the systemic circulation through a functional hepatic bypass would explain the apparently less efficient plasma clearance in fetuses without biliary diversion and would provide a partial explanation for the differences in onset of excretion and maximal rate of excretion observed in fetuses and adults with biliary cannulas. This general thesis is further supported by the direct demonstration of fetal intestinal absorption of bile salt in recent studies (18).

The existence of a functional hepatic bypass for bile salt absorbed from the fetal intestine has not yet been directly established. If such a fetal hepatic bypass exists, its nature must of course remain speculative. The ductus venosus may provide a potential anatomic shunt, fetal hepatic parenchymal cells may be less efficiently perfused by portal blood than in the adult liver (19), or perhaps the fetal system for bile salt uptake is not completely developed. Whichever mechanisms are involved, as noted above, the escape of measurable amounts of bile salt from portal to systemic circulations in the fetus offers an attractive explanation for the different plasma disappearance curves of the catheterized and uncatheterized fetuses and is consistent with the observed slower biliary excretion of intravenously infused cholate- ${ }^{14} \mathrm{C}$ in the fetus as compared with the adult. Whether fetal bile salt elimination is additionally limited by the degree of fetal hepatocellular transport, cannalicular secretion, or biliary reabsorption remains to be demonstrated.

The concentration of endogenous bile salt was 7-8 times higher in fetal gall bladder bile than in hepatic bile. In those fetuses with the biliary tree intact $\left(\mathrm{FD}_{1-3}\right)$, infused cholate $-{ }^{14} \mathrm{C}$ was mainly found in the gall bladder although up to $10 \%$ of the dose was recovered from the proximal small bowel. In contrast, when the fetal cystic duct was ligated and diverting biliary cannula was emplaced (FD4- $)$, no ${ }^{14} \mathrm{C}$ label was present in the gall bladder or intestine (Table II). These findings establish that bile salt is excreted by the fetal liver into the biliary tree and gall bladder, that the gall bladder has the functional capacity to concentrate bile, and that bile is delivered into the proximal small bowel. The gross functioning of the fetal biliary tree, therefore, resembles that of the adult.

Finally, there is evidence to suggest that bile salt excretion in the dog may closely resemble that in the subhuman primate. Although the fetal hepatic excretion of bilirubin shows marked species variation $(17,20,21)$, preliminary studies in fetal sheep ${ }^{2}$ and monkeys (22) have yielded results similar to those obtained in the present study in the dog.

The results establish that $1 \mathrm{wk}$ before birth the dog fetus has developed mechanisms for the uptake, conjugation, and excretion of bile salt. The biliary tree is functionally patent, the gall bladder serves as a concentrating reservoir, and bile is delivered into the intestine. Bile salt is reabsorbed from the fetal intestine, and indirect evidence suggests that, unlike the adult, a functional bypass permits the escape of absorbed bile salt into the systemic circulation.

\section{ACKNOWLEDGMENTS}

This work was supported in part by U. S. Public Health Service Grants AM 09881 and HD 01385.

${ }^{2}$ Smallwood, R. A., A. S. Brown, R. Lester, G. J. Piasecki, and B. T. Jackson. Unpublished data.

\section{REFERENCES}

1. Hofmann, A. F., and D. M. Small. 1967. Detergent properties of bile salts: correlation with physiological function. Annu. Rev. Med. 18: 333 .

2. Bergstrom, S., and H. Danielsson. 1968. Formation and metabolism of bile acids. In Handbook of Physiology. C. F. Code, editor. American Physiological Society, Washington, D. C. 5(Sect. 6) : 2391.

3. Hofmann, A. F. 1968. Functions of bile in the alimentary canal. In Handbook of Physiology. C. F. Code, editor. American Physiological Society, Washington, D. C. 5(Sect. 6) : 2507.

4. Hofmann, A. F. 1966. A physicochemical approach to the intraluminal phase of fat absorption. Gastroenterology. 50: 56.

5. Encrantz, J.-C., and J. Sjövall. 1957. Bile acids in newborn and adult humans. Acta Chem. Scand. 11: 1093. (Abstr.) 
6. Encrantz, J. C., and J. Sjovall. 1959. On the bile acids in duodenal contents of infants and children: bile acids and steroids 72. Clin. Chim. Acta. 4: 793.

7. Poley, J. R., J. C. Dower, C. A. Owen, Jr., and G. B. Strickler. 1964. Bile acids in infants and children. $J$. Lab. Clin. Med. 63: 838.

8. Bongiovanni, A. M. 1965. Bile acid content of gall bladder of infants, children and adults. J. Clin. Endocrinol. Metab. $25: 678$.

9. Peric-Golia, L., and H. Socic. 1968. Biliary bile acids and cholesterol in developing sheep. Amer. J. Physiol. 215: 1284 .

10. Jackson, B. T., and R. H. Egdahl. 1960. The performance of complex fetal operations in utero without amniotic fluid loss or other disturbances of fetal-maternal relationships. Surgery. 48: 564 .

11. Jackson, B. T., J. P. Clarke, and R. H. Egdahl. 1960. Direct lead fetal electrocardiography with undisturbed fetal-maternal relationships. Surg. Gynecol. Obstet. 110: 687.

12. Eneroth, P. 1969. Thin layer chromatography of bile alcohols and bile acids. In Lipid Chromatographic Analysis. G. V. Marinetti, editor. Marcel Dekker, Inc., New York. 2: 149.

13. Lester, R., and R. Schmid. 1963. Intestinal absorption of bile pigments. I. The enterohepatic circulation of bilirubin in the rat. J. Clin. Invest. 42: 736.

14. Oliverio, V. T., C. Denham, and J. D. Davidson. 1962.
Oxygen flask combustion in determination of $\mathrm{C}^{14}$ and $\mathrm{H}^{3}$ in biological materials. Anal. Biochem. 4: 188.

15. Hofmann, A. F. 1964. Thin-layer chromatography of bile acids and their derivatives. In New Biochemical Separations. A. T. James and L. J. Morris, editors. D. Van Nostrand, Co. Ltd., London. 261.

16. Admirand, W. H., and D. M. Small. 1968. The physicochemical basis of cholesterol gallstone formation in man. J. Clin. Invest. 47: 1043.

17. Bernstein, R. B., M. J. Novy, G. J. Piasecki, R. Lester, and B. T. Jackson. 1969. Bilirubin metabolism in the fetus. J. Clin. Invest. 48: 1678.

18. Smallwood, R. A., R. Lester, A. S. Brown, G. J. Piasecki, and B. T. Jackson. 1970. Fetal bile salt absorption. J. Clin. Invest. 49: 90a. (Abstr.)

19. Obrinsky, W., M. L. Denley, and R. W. Brauer. 1952. Sulphobromophthalein sodium excretion test as a measure of liver function in premature infants. Pediatrics. 9: 421.

20. Lester, R., R. E. Behrman, and J. F. Lucey. 1963. Transfer of bilirubin $-{ }^{14} \mathrm{C}$ across monkey placenta. Pediatrics. 32 : 416.

21. Schenker, S., R. A. Bashore, and F. Smith. 1967. Bilirubin disposition in foetal monkeys. In Bilirubin Metabolism. I. A. D. Bouchier and B. H. Billing, editors. Blackwell Scientific Publications Ltd., Oxford. 199.

22. Smallwood, R. A., R. Lester, G. J. Piasecki, J. M. Little, and B. T. Jackson. 1970. Bile salt metabolism in the fetal monkey. Gastroenterology. 58: 300. (Abstr.) 